\title{
Bone Marrow Stromal Cells Elicit Tissue Sparing after Acute but Not Delayed Transplantation into the Contused Adult Rat Thoracic Spinal Cord
}

\author{
Rishi D.S. Nandoe Tewarie, ${ }^{1,2 *}$ Andres Hurtado,,3* Gaby J. Ritfeld,,4 Sahar T. Rahiem, \\ Dane F. Wendell, Madalena M.S. Barroso, J. Andre Grotenhuis, ${ }^{1}$ and Martin Oudega ${ }^{5,6}$
}

\begin{abstract}
Bone marrow stromal cells (BMSC) transplanted into the contused spinal cord may support repair by improving tissue sparing. We injected allogeneic BMSC into the moderately contused adult rat thoracic spinal cord at 15 min (acute) and at 3, 7, and 21 days (delayed) post-injury and quantified tissue sparing and BMSC survival up to 4 weeks post-transplantation. BMSC survival within the contusion at 7 days post-transplantation was significantly higher with an acute injection (32\%) and 3-day delayed injection (52\%) than with a 7- or 21-day delayed injection $(9 \%$ both; $p<0.01)$. BMSC survival at 28 days post-transplantation was close to 0 in all paradigms, indicating rejection. In contused rats without a BMSC transplant (controls), the volume of spared tissue gradually decreased until $46 \%(p<0.001)$ of the volume of a comparable uninjured spinal cord segment at 49 days post-injury. In rats with BMSC, injected at $15 \mathrm{~min}, 3$, or 7 days post-injury, spared tissue volume was significantly higher in grafted rats than in control rats at the respective endpoints (i.e., 28, 31, and 35 days postinjury). Acute and 3-day delayed but not 7- and 21-day delayed injection of BMSC significantly improved tissue sparing, which was strongly correlated $(r=0.79-1.0)$ to BMSC survival in the first week after injection into the contusion. Our data showed that neuroprotective effects of BMSC transplanted into a moderate rat spinal cord contusion depend strongly on their survival during the first week post-injection. Acutely injected BMSC elicit more tissue sparing than delayed injected BMSC.
\end{abstract}

Key words: BMSC; cell survival; chronic; CNS injury; inflammation; neuroprotection

\section{Introduction}

A CONTUSION OF THE ADULT SPINAL CORD causes acute death of neural cells at the lesion epicenter and sets off a series of events resulting in additional tissue loss and the formation of cystic cavities (Hagg and Oudega, 2006). Transplantation of growth-promoting cells is considered a promising approach for repair of the contused spinal cord (Oudega and Xu, 2006; Barnett and Riddell, 2007).

Bone marrow stromal cells (BMSC) are among the candidates for cell-based spinal cord repair strategies (Nandoe Tewarie et al., 2006). These mesenchymal cells secrete growth factors that could support repair (Garcia et al., 2004; Mahmood et al., 2004; Song et al., 2004; Chen et al., 2005). Their potential was confirmed by the finding that transplantation of BMSC into the contused adult rat spinal cord resulted in functional recovery (Hofstetter et al., 2002; Wu et al., 2003; Ohta et al., 2004; Zurita and Vaquero, 2004, 2006). The mechanisms underlying these functional improvements observed after BMSC transplantation are incompletely understood.

A BMSC graft could contribute to repair by sparing spinal cord nervous tissue at the site of transplantation. It is known that BMSCs secrete brain-derived neurotrophic factor (BDNF)

\footnotetext{
${ }^{1}$ International Center for Spinal Cord Injury, Hugo W. Moser Research Institute at Kennedy Krieger, Baltimore, Maryland.

${ }^{2}$ Department of Neurosurgery, Radboud University Nijmegen Medical Center, Nijmegen, The Netherlands.

${ }^{3}$ Department of Neurology, Johns Hopkins University School of Medicine, Baltimore, Maryland.

${ }^{4}$ Department of Neurology, Leiden University Medical Center, Leiden, The Netherlands.

${ }^{5}$ Departments of Physical Medicine \& Rehabilitation and ${ }^{6}$ Neurobiology, University of Pittsburgh School of Medicine, Pittsburgh, Pennsylvania.

*These authors contributed equally to this study.
} 
(Mahmood et al., 2004), which has been implicated in limiting spinal cord tissue loss after injury (Ruitenberg et al., 2003). At present, the evidence for BMSC grafts to elicit tissue sparing in the injured spinal cord is still ambiguous (Wu et al., 2003; Ohta et al., 2004; Yoshihara et al., 2006).

Following an insult to the spinal cord, a cytotoxic environment develops at the injury epicenter to diminish in strength over time (Hagg and Oudega, 2006). Most likely these circumstances decrease the survival of cells transplanted into the lesion and consequently their effects on spinal cord repair. At present, quantitative evidence of the survival and neuroprotective effects of BMSCs transplanted into a spinal cord contusion is sparse, which obscures their spinal cord repair potential. We transplanted BMSCs into a moderately contused adult rat spinal cord at 15 min (acutely) and at 3, 7, and 21 days (delayed) post-injury and determined tissue sparing and BMSC survival up to 4 weeks posttransplantation.

\section{Methods}

\section{Timeline of the experiment}

Rats received a moderate contusion of the T9 spinal cord. Some of these rats received a BMSC injection into the injury epicenter at $15 \mathrm{~min}, 3,7$, or 21 days post-contusion. These BMSC-transplanted rats were euthanized at $15 \mathrm{~min}, 3,7$, and 28 days post-injection. Other contused rats did not receive the BMSC injection (control rats) and, to match survival times of the BMSC-transplanted rats, were euthanized at $15 \mathrm{~min}$, and $3,7,10,14,21,24,28,31,35$, and 49 days post-injury. Their spinal cords were removed and prepared for histology to enable analysis of tissue sparing and BMSC numbers. Details on the used techniques are described below.

\section{Animals}

Adult female Sprague-Dawley rats $(\mathrm{n}=121,160-180 \mathrm{~g}$; Harlan, Indianapolis, IN) were used in these experiments. All animals were housed according to the guidelines of the $\mathrm{Na}$ tional Institutes of Health and the United States Department of Agriculture. The institutional Animal Care and Use Committees of the University of Miami and Johns Hopkins University approved all surgical procedures.

\section{Culture and lentiviral transduction of BMSCs}

BMSCs were obtained from the marrow of femurs and tibias of adult female Sprague-Dawley rats $(n=8)$, according to a previously published protocol (Azizi et al., 1998). Passage 0 cells were infected with lentiviral vectors (LV) encoding for green fluorescent protein (GFP) at an MOI of 150. The vectors were generated using the ViraPower Lentiviral Expression System (Invitrogen, Carlsbad, CA) (Blits et al., 2005). Expression was under control of the human cytomegalovirus promoter and the Woodstuck hepatitis virus posttranscriptional regulatory element (Naldini et al., 1996). The titer of the lentiviral stocks varied from $1-3 \times 10^{9} \mathrm{TU} / \mathrm{mL}$. Only passage 3 cultures with a transduction rate of about $95 \%$ were used for transplantation.

With enzyme-linked immune sorbent assays (ELISA) we determined whether the BMSC secreted BDNF and glial cellderived neurotrophic factor (GDNF). For this, medium of nearly confluent passage 3 cultures (with an average of $2 \times 10^{6}$ cells) was refreshed, removed $24 \mathrm{~h}$ later, and used for BDNF ELISA (BDNF Emax ImmunoAssay System, Promega, Madison, WI) and GDNF ELISA (GDNF Emax ImmunoAssay System, Promega) according to the manufacturer's instructions. Standard curves of the ELISA kits were linear between 7.8 and $500 \mathrm{pg} / \mathrm{mL}$ for BDNF and 15.6 and $1000 \mathrm{pg} / \mathrm{mL}$ for GDNF. ELISAs were analyzed with a microplate reader (SpectraMax M5, Molecular Devices, Sunnyvale, CA). The cells in culture secreted $14.1 \mathrm{pg} / \mathrm{mL} / 24 \mathrm{~h}$ of BDNF. The amount of GDNF was below the reliability level of the ELISA.

\section{Contusion injury}

The rats $(n=108)$ were anesthetized with $1-2 \%$ isoflurane in oxygen and their backs were shaved and cleaned with Betadine and $70 \%$ alcohol. Lacrilube ophthalmic ointment (Allergen Pharmaceuticals, Irvine, CA) was applied to the eyes and gentamicin $(1.2 \mathrm{mg}$ in $0.03 \mathrm{~mL}$; Abbott Laboratories, North Chicago, IL) was injected intramuscularly. During surgery, rats were kept on a heating pad to maintain their body temperature at $37 \pm 0.5^{\circ} \mathrm{C}$. A laminectomy was performed at the eighth thoracic vertebra to expose the ninth thoracic spinal cord segment, which was subsequently moderately contused (10 g, $12.5 \mathrm{~mm}$ NYU impactor) (Gruner, 1992). To ensure consistency among contused rats, the contusion impact velocity and compression were monitored and all rats with $>5 \%$ error in these measurements were removed from the study. Rats that remained in the study displayed hindlimb paralysis and scored $<3$ at 1 day and $<7$ at 3 days post-injury on the Basso-Beattie-Bresnahan (BBB) scale (Basso et al., 1995). Implementation of these criteria ensured appropriateness of the contusion injury and consistency among the experimental animals. All laminectomies and injuries were performed by the same investigator. After injury, overlying muscles were sutured in layers and the skin was closed with metal wound clips. The rats received $10 \mathrm{~mL}$ Ringer's solution subcutaneously and $1.2 \mathrm{mg}$ gentamicin intramuscularly. The rats were kept in a small animal incubator at $37^{\circ} \mathrm{C}$ until full recovery and then returned to their cages with ad libitum access to water and food. During the first week post-injury, $1.2 \mathrm{mg}$ gentamicin was administered intramuscularly on a daily basis. The analgesic buprenorphine $(0.006 \mathrm{mg}$; Buprenex, Reckitt Benckiser, Richmond, VA) was administered subcutaneously immediately after surgery and once for the next 3 days. The bladders were expressed manually twice a day until reflex bladder function returned. Urinary tract infection did not occur in any of the rats.

\section{BMSC transplantation}

Contused rats were anesthetized with an intramuscular injection of $25.7 \mathrm{mg} / \mathrm{kg}$ ketamine, $5.14 \mathrm{mg} / \mathrm{kg}$ xylazine, and $0.85 \mathrm{mg} / \mathrm{kg}$ acepromazine, and their contused spinal cord was exposed. A total of $1 \times 10^{6}$ BMSC in $5 \mu \mathrm{L}$ DMEM was injected into the contusion epicenter using techniques described previously (Hurtado et al., 2006). BMSC injections were made at $15 \mathrm{~min}, 3,7$, and 21 days post-contusion. In the $15 \mathrm{~min}$ group, the rats remained sedated with the contused spinal cord covered with a saline-moistened gauze until BMSC injection. All transplantations were performed by the same investigator. After injection, muscles were sutured in layers and the skin closed with metal wound clips. Post-surgery care was as described above. 


\section{Assessment of BMSC viability during the injection procedures}

The effects of the injection procedures on the number of BMSCs were determined in vitro using the same tools and methods as those used for actual transplantation. First, we assessed the viability of $1 \times 10^{6}$ BMSC in $5 \mu \mathrm{L}$ DMEM in an Eppendorf tube after $5 \mathrm{~h}$ on ice (the typical length of a transplantation session). A sample of these cells was stained with Trypan Blue (1:1; Sigma, St. Louis, MO) and the percentage of living (unstained) BMSCs was calculated using a hemocytometer. Second, we assessed BMSC viability after injection. BMSCs in DMEM were kept on ice for $5 \mathrm{~h}$ and then injected into an Eppendorf tube $\left(1 \times 10^{6}\right.$ BMSC in $5 \mu \mathrm{L}$ DMEM per tube $)$ using the same pulled glass injection needle attached to a Hamilton syringe as used for transplantation into the rat spinal cord. These cells were then kept at $37^{\circ} \mathrm{C} / 5 \% \mathrm{CO}_{2}$ for 1 , 3 , and $5 \mathrm{~h}$ ( $\mathrm{n}=3$ for each time point). BMSCs that were not passed through the glass needle and kept in the incubator for the same time periods served as controls $(\mathrm{n}=3$ for each time point). At the selected times, and immediately after passing through the glass needle (time point 0 ), cells were stained with Trypan Blue (1:1) and the percentage of living (unstained) BMSCs was calculated using a hemocytometer. The effect of passing through the glass needle was determined by the difference in the percentages of living BMSC between control and time point 0 cells. Whether the incubation conditions had affected BMSC death in time was calculated from the difference in viability between control cells and cells that were passed through the glass needle at 1,3 , and $5 \mathrm{~h}$. Third, we determined how many cells passed through the needle. A sample of $1 \times 10^{6}$ BMSC in $5 \mu \mathrm{L}$ DMEM that was injected into an Eppendorf tube using a pulled glass needle attached to a Hamilton syringe was stained with trypan blue to calculate the total number of living (unstained) BMSCs using a hemocytometer.

\section{Histological procedures}

At $15 \mathrm{~min}, 3,7$, and 28 days after BMSC injection, rats were anesthetized as above (note that the 15-min group remained anesthetized until fixation). Control rats that were contused but did not receive a BMSC transplant were anesthetized $15 \mathrm{~min}$, and $3,7,10,14,21,24,28,31,35$, and 49 days postinjury. These time points correspond with the survival times of the BMSC-transplanted rats. After deep sedation was confirmed, the heart was exposed and $0.1 \mathrm{~mL}$ Heparine (500 IU; Henry Schein, Melville, NY) injected into the left ventricle. Next, $500 \mathrm{~mL}$ saline followed by $500 \mathrm{~mL}$ ice-cold $4 \%$ paraformaldehyde in phosphate buffer (PB; 0.1 M, pH 7.4) was pumped through the vascular system. The spinal cord was removed and kept overnight in the same fixative at $4{ }^{\circ} \mathrm{C}$. Then a $15 \mathrm{~mm}$ long segment of the spinal cord centered at the contusion was dissected out, kept in phosphate-buffered $30 \%$ sucrose $(0.1 \mathrm{M}, \mathrm{pH} 7.4)$ for $48 \mathrm{~h}$, and frozen within Shandon M-1 Embedding Matrix (Thermo Electron Corporation, Pittsburgh, PA). From these blocks, $20 \mu \mathrm{m}$ thick horizontal sections were cut on a cryostat, mounted onto glass slides, and stored at $-20^{\circ} \mathrm{C}$.

From some rats of each group, a $1 \mathrm{~mm}$ thick section was taken from the epicenter of the lesion for preparation of semithinplastic sections for light microscopy. The $1 \mathrm{~mm}$ thick tissue blocks were kept in $2 \%$ glutaraldehyde with $3 \%$ sucrose in $\mathrm{PB}$ for at least $24 \mathrm{~h}$ at $4^{\circ} \mathrm{C}$, in $1 \%$ osmium tetraoxide in $\mathrm{PB}$ for 12-16h, dehydrated, and embedded in Epon-Araldite (Electron Microscopy Services, Fort Washington, PA). One $\mu \mathrm{m}$ thick transverse sections were cut on a Reichert-Jung ultramicrotome, stained with a $1 \%$ toluidine blue- $1 \%$ methylene blue- $1 \%$ sodium borate solution, and used to analyze general histology of the spinal cord and transplant and determine tissue loss at the injury/transplant epicenter.

\section{Measurement of spinal cord tissue sparing}

Sparing of spinal cord tissue was assessed in a blinded fashion in horizontal cresyl violet-stained cryostat sections using the Cavalieri estimator function of Stereo Investigator (MBF Bioscience, Williston, VT). All measurements were taken by the same investigator. From each animal, every tenth cryostat section (200 $\mu \mathrm{m}$ intervals) was used to determine the volume of a $5 \mathrm{~mm}$ long segment centered at the contusion/ transplantation epicenter and that of spared tissue within this segment. Tissue was considered spared if it lacked cavities, areas with high density of infiltrating small cells, resembling neutrophils and lymphocytes, and neurons with darkly stained cytoplasmic Nissl bodies (Takami et al., 2002). The volume of spared tissue was expressed as a percentage of the average volume of a comparable uninjured spinal cord segment.

\section{Measurement of BMSC number within the contused spinal cord}

From each rat transplanted with BMSCs, every tenth cryostat section was covered with a glass slip with Vectashield with DAPI (4'-6-diamidino-2-phenylindole, Vector Laboratories, Burlingame, CA) and used to determine the number of GFPpositive BMSCs in the contusion. In these sections, in a blinded fashion, the contusion area with GFP-positive cells was outlined under a $2.5 x$ objective. Then, under a $63 x$ objective (oil immersion), grids of 250 by $250 \mu \mathrm{m}$ (counting frame area, $625 \mu \mathrm{m}^{2}$ ) were placed over the outlined area and each GFPpositive cell with a recognizable nucleus was counted using the optical fractionator function of Stereo Investigator (MBF Bioscience, Williston, VT). The sampling interval was: $\mathrm{x}=250 \mu \mathrm{m}, \mathrm{y}=250 \mu \mathrm{m}$. All measurements were taken by the same investigator. The resulting numbers were used to calculate the total number of GFP-positive BMSC within the contusion. These total numbers were then expressed as a percentage of the total number found at $15 \mathrm{~min}$ post-injection.

\section{Assessment of BMSC migration}

We found that transplanted BMSC had migrated away from the injection site. Their number, location, and distance from the contusion epicenter were determined in one series of cryostat sections of each of the transplanted rats. Because it is possible that BMSC had migrated beyond $8 \mathrm{~mm}$, which was the approximate distance from the injury epicenter to the edge of the section in rostral and caudal direction, we also sectioned and examined the contiguous $10 \mathrm{~mm}$ long rostral and caudal spinal cord segment. All GFP-positive BMSC outside of the contusion were counted manually under a 40x objective.

\section{Statistical analysis}

We used Sigmastat (Systat Software, San Jose, CA) for the statistical analyses. The $t$ test was used to determine differences between groups, which were accepted at $p<0.05$. The 


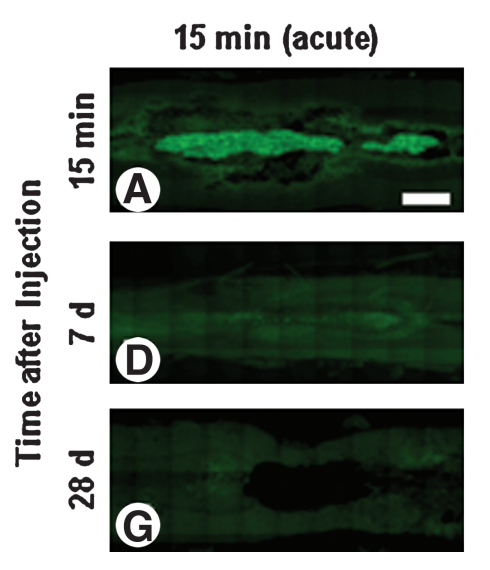

\section{Time of Injection}

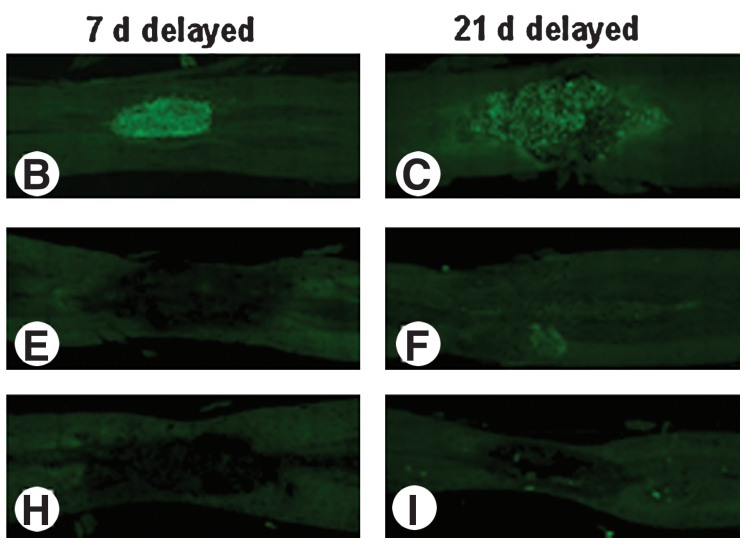

FIG. 1. BMSC transplants within a moderate contusion in the adult rat thoracic spinal cord decrease in size during 28 days post-injection. The transplant is shown at $15 \mathrm{~min}(\mathbf{A}-\mathbf{C}), 7$ days (D-F), and 28 days (G-I) after an injection at $15 \mathrm{~min}$ (acute), 7 days, and 21 days, respectively, post-injury. All microphotographs are from horizontal cryostat sections. (A) Scale bar, $600 \mu \mathrm{m}$ in A-I.

relationship between tissue sparing and BMSC number was determined by the Pearson correlation coefficient $(r)$.

\section{Results}

\section{BMSC transplants in the contused spinal cord}

With all transplantation paradigms, GFP-positive BMSCs were found within the contusion at $15 \mathrm{~min}$ after the injection (Fig. 1A-C). The number of BMSCs within the contusion was noticeably decreased at 7 days (Fig. 1D-F) and 28 days (Fig. $1 \mathrm{G}-\mathrm{I})$ after injection.

\section{Spared tissue in the contused adult rat spinal cord}

We qualitatively assessed the contused spinal cord segment of adult rats without (controls) and with a BMSC transplant using toluidine blue-stained transverse semi-thin plastic sections of the contusion epicenter and cresyl violet-stained horizontal cryostat sections of the contused spinal cord segment (Fig. 2). In transverse plastic sections, a loosely organized transplant that filled up the contusion was found at 3 days after an acute injection (Fig. 2A). At 28 days after a BMSC injection into the 21-day-old contusion, the spinal cord was not only decreased in size but also contained one or more
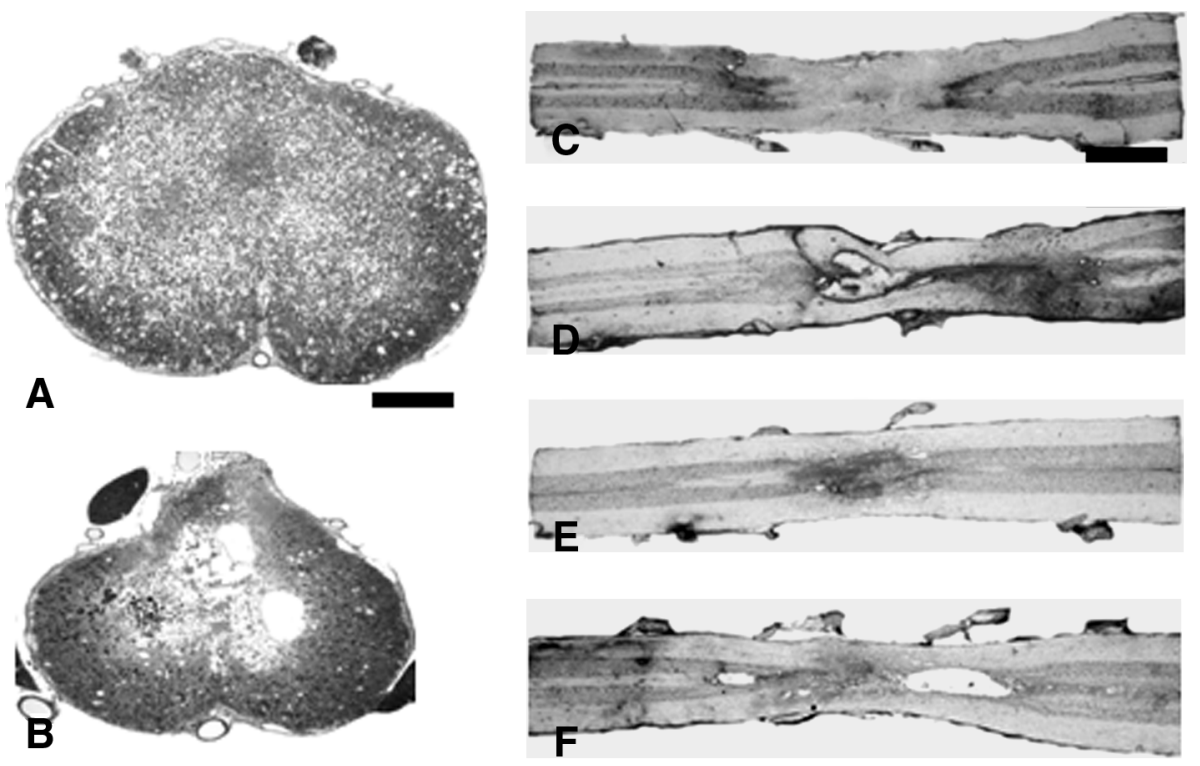

FIG. 2. Spared tissue in the contused adult rat spinal cord after BMSC transplantation. (A) Loosely organized tissue in contusion epicenter at 3 days after an acute BMSC injection. (B) Cavities present in the contusion epicenter at 28 days after a 21-day delayed transplantation of BMSCs. Note that the spinal cord has also decreased in size. (C) At 3 days after acute BMSC injection, damaged tissue but not cavities was observed. (D) At 28 days after acute injection, large cavities were found in the contused segment. (E) With a 7-day delayed BMSC injection, damaged tissue and a few small cavities were found at 3 days post-transplantation. (F) At 28 days after BMSC injection into the 7-day-old contusion, large cavities were found in the contused segment. Images are from toluidine blue-stained transverse semithin plastic sections (A and B). Images are from cresyl violetstained horizontal cryostat sections (rostral to the left) (C-F). (A) Scale bar, $150 \mu \mathrm{m}$ in A and B; (C) scale bar, $600 \mu \mathrm{m}$ in C-F. 
Table 1. Comparison of Volumes of Spared (Intact) Tissue in Contused Spinal Cord Segments in Rats With AND Without BMSC Transplant

\begin{tabular}{|c|c|c|c|c|c|}
\hline Time of $\mathrm{Tr}$ & Time after $\mathrm{Tr}$ & BMSC transplant & Controls (no BMSC) & Time after con & $\%$ of control \\
\hline \multirow[t]{4}{*}{$15 \mathrm{~min}$} & $15 \mathrm{~min}$ & $20.6 \pm 3.6$ & $22.3 \pm 1.9$ & $15 \mathrm{mo}$ & -7.6 \\
\hline & $3 \mathrm{~d}$ & $19.3 \pm 1.4$ & $18.7 \pm 1.1$ & $3 d$ & 3.2 \\
\hline & $7 d$ & $16.6 \pm 1.8$ & $13.2 \pm 0.8$ & $7 d$ & $25.8^{* *}$ \\
\hline & $28 \mathrm{~d}$ & $15.7 \pm 0.8$ & $11 \pm 1.6$ & $28 \mathrm{~d}$ & $42.7^{* * *}$ \\
\hline \multirow[t]{4}{*}{$3 d$} & $15 \mathrm{~min}$ & $18.4 \pm 1.2$ & $18.7 \pm 1.1$ & $3 d$ & -1.6 \\
\hline & $3 \mathrm{~d}$ & $16.8 \pm 0.9$ & $13.2 \pm 1.4$ & $7 \mathrm{~d}$ & $27.3^{* *}$ \\
\hline & $7 \mathrm{~d}$ & $16.2 \pm 1.4$ & $13.9 \pm 1.2$ & $10 \mathrm{~d}$ & $16.5^{*}$ \\
\hline & $28 \mathrm{~d}$ & $15.8 \pm 1.8$ & $11.8 \pm 2.2$ & $31 \mathrm{~d}$ & $33.9^{* *}$ \\
\hline \multirow[t]{4}{*}{$7 \mathrm{~d}$} & $15 \min$ & $14.1 \pm 1.2$ & $13.2 \pm 0.8$ & $7 \mathrm{~d}$ & 6.8 \\
\hline & $3 d$ & $14.4 \pm 0.9$ & $13.9 \pm 1.2$ & $10 \mathrm{~d}$ & 3.6 \\
\hline & $7 d$ & $13.2 \pm 0.6$ & $12.2 \pm 1.2$ & $14 \mathrm{~d}$ & 8.2 \\
\hline & $28 \mathrm{~d}$ & $12.7 \pm 1.1$ & $11.8 \pm 1.7$ & $35 \mathrm{~d}$ & 7.6 \\
\hline \multirow[t]{4}{*}{$21 \mathrm{~d}$} & $15 \min$ & $13.2 \pm 1.2$ & $12.2 \pm 1.7$ & $21 \mathrm{~d}$ & 8.2 \\
\hline & $3 d$ & $13.1 \pm 1.4$ & $11.9 \pm 1.3$ & $24 d$ & 10.1 \\
\hline & $7 \mathrm{~d}$ & $12.8 \pm 0.8$ & $11 \pm 1.6$ & $28 \mathrm{~d}$ & 16.4 \\
\hline & $28 \mathrm{~d}$ & $11.5 \pm 0.9$ & $10.1 \pm 1.7$ & $49 \mathrm{~d}$ & 13.9 \\
\hline
\end{tabular}

Rats were contused and received a BMSC transplant $(\mathrm{Tr})$ at $15 \mathrm{~min}, 3,7$, or 21 days post-injury (column 1). The transplanted rats were euthanized at $15 \mathrm{~min}, 3,7$, or 28 days after BMSC injection (column 2). The spinal cords were removed and histologically prepared to determine the volumes of spared (intact) tissue (column 3, $\pm \mathrm{SD}$ ). These were then compared to those in control rats, which were similarly contused but did not receive BMSCs (column 4, $\pm \mathrm{SD}$ ). Survival times of control rats after contusion (con; column 5) were matched with the total survival times (i.e., pre-injection time plus post-injection time) of BMSC-injected rats. The difference (as percentage of the volume in controls) was calculated and tested for significance (column 6). A positive value indicates more spared (intact) tissue in the BMSCtransplanted spinal cord. No asterisks, not significant; ${ }^{*} p<0.05 ;{ }^{* *} p<0.03 ;{ }^{* * *} p<0.01$.

large cavities (Fig. 2B). On horizontal sections, after an acute injection, cavities were not present at 3 days (Fig. 2C) but could be found at 28 days (Fig. 2D). With a 7-day delayed injection, small cavities were found at 3 days (Fig. 2E) and much larger ones at 28 days (Fig. $2 \mathrm{~F}$ ) post-injection.

Using Stereo Investigator software, we determined that the volume of spared tissue in the contused spinal cord segment gradually decreased to $10.1 \pm 1.7 \mathrm{~mm}^{3}$ at 49 days post-injury in control rats and to $11.5 \pm 0.9 \mathrm{~mm}^{3}$ at 49 days post-injury in BMSC-transplanted rats (Table 1). Because narrowing of the contused segment occurs, we determined the volume of spared tissue relative to that of a comparable segment from uninjured and untreated spinal cord $\left(21.9 \pm 3.4 \mathrm{~mm}^{3}\right.$; SD, $\mathrm{n}=5$; Fig. 3A). We found that with BMSCs injected at $15 \mathrm{~min}$, 3 days, or 7 days after injury the volume of spared tissue was significantly higher in transplanted rats than in control rats at the respective endpoints (i.e., 28, 31, and 35 days post-injury).

We then determined the relative change in spared tissue volume in transplanted and control rats between the same time periods after contusion (Fig. 3B). Importantly, in BMSCtransplanted rats the volume of spared tissue at $15 \mathrm{~min}$ after injection was similar to that found in control rats of matching survival times. The results show that tissue sparing during the 28 days that BMSCs were present was increased with acute and 3-day delayed but not 7- and 21-day delayed BMSC transplantation compared to the loss that occurs in control rats within the same time periods.

\section{Loss of BMSCs transplanted into the moderately contused rat spinal cord}

We found that $95 \%$ of BMSC survived a period of $5 \mathrm{~h}$ on ice and $92 \%$ survived when passed through a pulled glass needle. Thus, our methods could have resulted in a maximum of $13 \%$ death among BMSCs injected into the contusion. From the intended 1 million cells, $6.7 \times 10^{5}$ BMSC passed through the needle alive. Taking the greatest possible percentage of deaths due to transplantation into account, this implies that $8 \times 10^{5}$ BMSCs were injected into the contusion of which $1.3 \times 10^{5}$ cells $(13 \%)$ were dead. To correct for variability due to our procedures, BMSC numbers were expressed as a percentage of the number found at $15 \mathrm{~min}$ post-injection.

At 15 min post-injection, we found that $35 \%, 25 \%, 58 \%$, and $32 \%$ of the calculated average of $6.7 \times 10^{5}$ (live) BMSCs were present and alive in the contusion with the injection made at $15 \mathrm{~min}, 3,7$, and 21 days post-injury, respectively. There was no direct relationship between the percentages and the timing of the injection; cell loss during the first 15 min post-injection was $35 \%$ with acute and $38 \%$ with delayed paradigms.

The average BMSC numbers and corresponding percentages (relative to the number at $15 \mathrm{~min}$ post-injection) are listed in Table 2 and Figure $4 \mathrm{~A}$ and reveal that the number of BMSC at 7 days post-injection was significantly higher after acute $(p<0.01)$ and 3-day delayed $(p<0.005)$ injections compared to 7 - and 21-day delayed injections: $32 \%$ and $52 \%$ vs. $9 \%$ and $9 \%$, respectively (Fig. 4B). The number of BMSCs in the contusion at 28 days post-injection was close to 0 in all groups, indicating rejection of the transplanted cells.

\section{Tissue sparing and BMSC survival are strongly associated}

The relationship between tissue sparing and BMSC survival was assessed using the Pearson correlation coefficient. We found that with an acute and 3-days delayed injection, the positive correlation was large with $r=1.0$ at 3,7 , and 28 days post-injection. With a 7-day delayed injection, the positive correlation was large with $r=0.79$ at 3 days and with $r=1.0$ at 7 and 28 days post-injection. With a 21-day delayed injection, there was no correlation between BMSC number and spared 

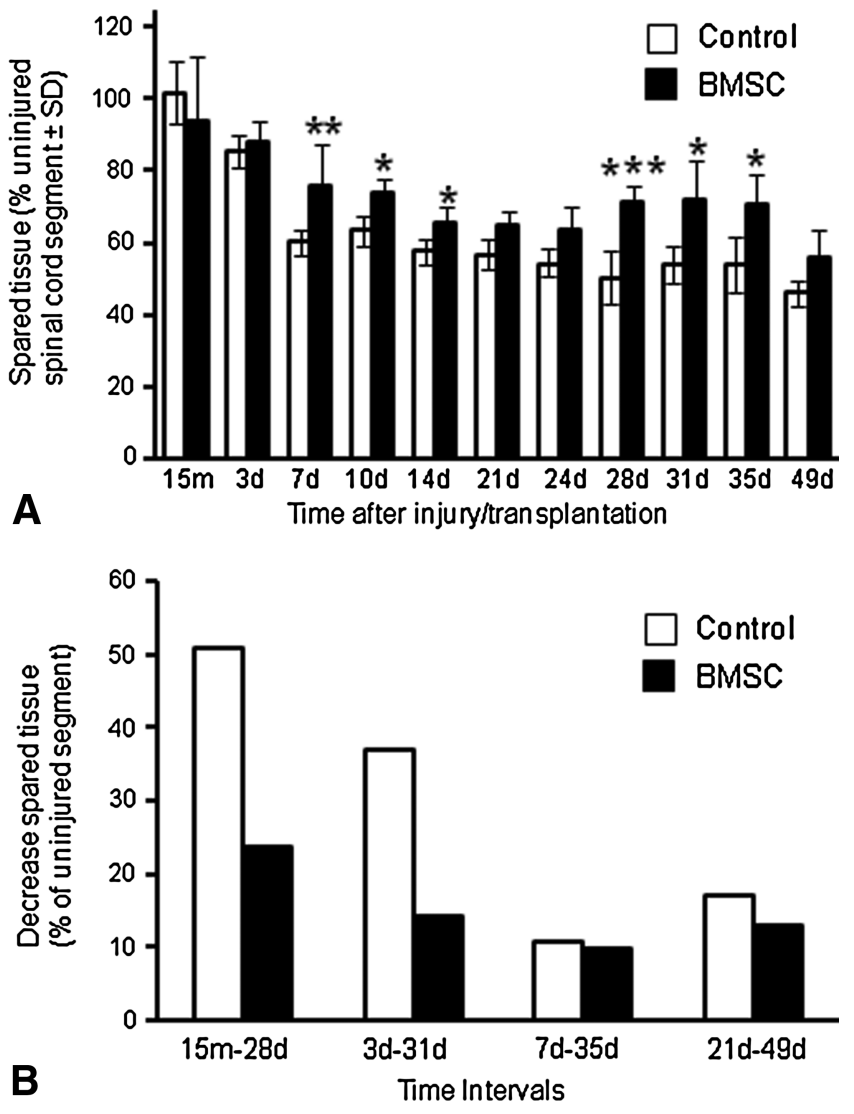

FIG. 3. BMSC transplantation elicits tissue sparing in the contused adult rat spinal cord. (A) Bar graph showing the volumes of spared tissue in the contused spinal cord segment in rats without (control, open bars) and with (closed bars) BMSC transplants. Spared tissue volume is expressed as a percentage of the volume of a comparable uninjured spinal cord segment. Time points of the x-axis refer to control rats. The survival times of BMSC-transplanted rats that matched these time points were $15 \mathrm{~m} / 15 \mathrm{~m}, 15 \mathrm{~m} / 3 \mathrm{~d}, 15 \mathrm{~m} / 7 \mathrm{~d}$, $3 \mathrm{~d} / 7 \mathrm{~d}, 7 \mathrm{~d} / 7 \mathrm{~d}, 21 \mathrm{~d} / 15 \mathrm{~m}, 21 \mathrm{~d} / 3 \mathrm{~d}, 15 \mathrm{~m} / 28 \mathrm{~d}, 3 \mathrm{~d} / 28 \mathrm{~d}$, $7 \mathrm{~d} / 28 \mathrm{~d}$, and $21 \mathrm{~d} / 28 \mathrm{~d}$ (see also Table 1). Asterisks indicate a significant difference control and BMSC transplanted rats $\left({ }^{*} p<0.05 ;{ }^{* *} p<0.03 ;{ }^{* * *} p<0.01\right)$. (B) Decrease in spared tissue volume occurring during the 28 -day time period. The volume at the endpoint is expressed as a percentage of the volume at the starting point. The time periods refer to control rats. The matching time points of transplanted rats are listed above.

tissue volume. Thus, in groups that received the BMSC transplant during the first week post-contusion, we found a strong positive association between tissue sparing and BMSC survival with $r$ values between 0.79 and 1.0.

\section{BMSC migration into adjacent spinal nervous tissue}

The number of BMSCs in the transplant site could decrease as BMSC migrate away from the injection site. We found that a few days after injection BMSCs started to migrate away mainly from the rostral and caudal aspects of the transplant (Fig. 5A). One week after injection, BMSCs were found in the dorsal and ventral columns, some as far as $7 \mathrm{~mm}$ away from the contusion epicenter. Most of these cells were spindle- shaped with a small nucleus and several extensions (Fig. 5B). With a 3-day post-injury injection, a total of $2100 \pm 849$ BMSCs at 7 days and $820 \pm 99$ at 28 days post-transplantation had migrated away from the transplant site (Fig. 5C). Significantly more BMSCs $(p<0.001)$ were found rostral $(80 \pm 14 \%)$ than caudal $(20 \pm 9 \%)$ to the transplantation site. The total number of migrated BMSCs represented $1.2 \%$ of the number of BMSCs in the contusion at $15 \mathrm{~min}$ post-injection and $2.4 \%$ of the number at 7 days post-injection. At 28 days post-injection, almost twice as many BMSCs were found outside of the contusion compared to within. Thus, BMSCs that had migrated away from the injection site into the adjacent spinal cord tissue appeared to be protected compared to those that remained within the contusion.

\section{Discussion}

Survival of BMSCs transplanted acutely ( $15 \mathrm{~min}$ postinjury) or delayed (3, 7, and 21 days post-injury) into a moderately contused adult rat spinal cord is low with few or none of the cells left at 28 days post-injection. BMSC loss at the 7 -day post-injection time point was $68 \%$ with acute and $48 \%$ with 3-day delayed injections, which was significantly lower than with 7- and 21-day (91\% both) delayed injections. This indicates that the contusion environment is more deleterious to transplanted BMSCs during the second and fourth weeks after impact than during the first week after impact. In control rats, the amount of spared tissue gradually decreased in time until $46 \%$ of that in a comparable uninjured spinal cord segment at 49 days post-injury. The presence of BMSCs resulted in increased amounts of spared tissue compared to controls. Acute and 3-day delayed, but not 7- and 21-day delayed, injection of BMSCs significantly improved tissue sparing. There was a large positive correlation between spared tissue volume and BMSC number with injections during the first week postcontusion.

Effects of BMSCs on tissue sparing were assessed by determining the volume of spared (intact) tissue (see above for criteria; also see Takami et al., 2002) within the contused spinal cord segment. This revealed an increased volume of spared tissue at 7 and 28 days post-injury with an acute BMSC injection and at 6, 10, and 31 days post-injury with a 3-day delayed BMSC injection. This particular approach of measuring spared tissue is employed regularly but it does not take into account narrowing of the spinal cord, which typically occurs after a contusion. Therefore, we also determine the volume of spared tissue relative to that of a comparable segment from uninjured and untreated spinal cord (Takami et al., 2002). This revealed an increased volume of spared tissue at the above-mentioned time points but also at 35 days postinjury with a 7-day delayed BMSC injection.

Our results demonstrated that acutely transplanted BMSCs contributed to sparing of nervous tissue following a moderate contusion of the thoracic rat spinal cord better than delayed transplanted BMSCs did. The reduced loss of the acutely transplanted BMSCs during the first week after injection correlated closely with the increased volumes of tissue sparing. Previously, it was reported that acutely transplanted BMSCs reduced the size of cavities at 3 weeks after an injection into the contusion (Wu et al., 2003) and at 5 weeks after an injection into the fourth ventricle (Ohta et al., 2004). In the present study, we have assessed spared tissue volume relative 
Table 2. Number of BMSCs in Contusion at Different Time Points after Injection

\begin{tabular}{|c|c|c|c|c|c|}
\hline Time of $\mathrm{Tr}$ & Time after $\mathrm{Tr}$ & No. of BMSC $( \pm S D)$ & $\%$ of no. at $15 \mathrm{mo}( \pm S D)$ & P values within & P values between \\
\hline \multirow[t]{4}{*}{$15 \mathrm{~min}$} & $15 \min$ & $234064 \pm 50568$ & 100 & & n.s. \\
\hline & $3 d$ & $137818 \pm 13710$ & $59 \pm 6$ & $* * *$ & $\&$ \\
\hline & $7 \mathrm{~d}$ & $75123 \pm 6206$ & $32 \pm 3$ & $* * *$ & $\#$ \\
\hline & $28 \mathrm{~d}$ & $650 \pm 1170$ & $0 \pm 1$ & $* * *$ & n.s. \\
\hline \multirow[t]{4}{*}{$3 d$} & $15 \mathrm{~min}$ & $168159 \pm 10829$ & 100 & & n.s. \\
\hline & $3 \mathrm{~d}$ & $117954 \pm 19405$ & $70 \pm 12$ & $* * *$ & $\& \&$ \\
\hline & $7 \mathrm{~d}$ & $87678 \pm 13034$ & $52 \pm 8$ & $* * *$ & \#\# \\
\hline & $28 \mathrm{~d}$ & $450 \pm 495$ & $0 \pm 0$ & $* * *$ & n.s. \\
\hline \multirow[t]{4}{*}{$7 \mathrm{~d}$} & $15 \mathrm{~min}$ & $387372 \pm 38015$ & 100 & & n.s. \\
\hline & $3 d$ & $177267 \pm 23869$ & $46 \pm 4$ & $* * *$ & \\
\hline & $7 \mathrm{~d}$ & $36350 \pm 3465$ & $9 \pm 1$ & $* * *$ & \\
\hline & $28 \mathrm{~d}$ & $1325 \pm 2650$ & $0 \pm 1$ & $* * *$ & n.s. \\
\hline \multirow[t]{4}{*}{$21 \mathrm{~d}$} & $15 \mathrm{~min}$ & $217619 \pm 29273$ & 100 & & n.s. \\
\hline & $3 d$ & $83300 \pm 11281$ & $38 \pm 5$ & $* * *$ & \\
\hline & $7 d$ & $19154 \pm 4107$ & $9 \pm 2$ & $* * *$ & \\
\hline & $28 \mathrm{~d}$ & $4300 \pm 3387$ & $2 \pm 2$ & $* * *$ & n.s. \\
\hline
\end{tabular}

Rats were contused and received BMSC transplants (Tr) at $15 \mathrm{~min}, 3,7$, or 21 days post-injury (column 1). The rats were euthanized at $15 \mathrm{~min}, 3,7$, or 28 days after injection (column 2) and the spinal cord was histologically prepared to determine the number of GFP-positive BMSC within the contusion using stereology (column 3). These numbers were expressed as a percentage of the number at 15 min after injection for each group (column 4). Within each group (i.e., injection paradigm; column 5), BMSC numbers at 3, 7, and 28 days post-injection were significantly lower $\left.{ }^{* * *} p<0.01\right)$ compared to the previous time points $(15 \mathrm{~min}, 3$, and 7 days), demonstrating the significant gradual decrease in BMSC number regardless of the injection time. Between groups, at the same time point (column 6), BMSC number at 15 min postinjection was not different (n.s.). BMSC number at 3 days post-injection was significantly higher with acute $(\& p<0.05)$ and 3 -day delayed injections $(\& \& p<0.03)$ compared to 21-day delayed injections. BMSC number at 7 days post-injection was significantly higher with acute $(\# p<0.01)$ and 3 -days delayed $(\# \# p<0.005)$ compared to 7 - and 21-day delayed injections. BMSC number at 15 min and 28 days postinjection were not different (n.s.).

to that of a comparable segment from an uninjured and untreated spinal cord to account for the normally occurring shrinkage. Despite this difference in approach, our results are in agreement as they indicated that acutely transplanted BMSC exert neuroprotective actions on the nervous tissue within the contused segment. The effects of these neuroprotective actions remain visible until 28 days post-transplantation. In 2006, Yoshihara and collaborators demonstrated that BMSC transplantation into a 9-day-old moderate contusion did not result in neuroprotection within the contused segment, which is in concurrence with our findings that delayed transplanted BMSCs fail to exert neuroprotective actions. One potential mechanism by which transplanted BMSCs result in neuroprotection may be by secreting BDNF (Ruitenberg et al., 2003; Patist et al., 2004). We used ELISA to confirm that the BMSCs used for transplantation in our study produced and secreted BDNF. Future studies in which the production of BDNF by BMSCs or the actions of BDNF are blocked will help to elucidate the role of BMSC-derived BDNF on neuroprotection.

Our data showed that $0.02 \%$ of acutely transplanted BMSC s had survived up to 28 days in a moderate spinal cord contusion. In a previous study, it was shown that $0.17 \%$ of BMSC acutely injected into and near a moderate-severe contusion ( $25 \mathrm{~mm}$, NYU impactor) in the rat spinal cord had survived at 5 weeks post-injury/injection (Hofstetter et al., 2002). When BMSCs were grafted into a 7-day-old contusion, six times more cells $(0.99 \%)$ had survived at 5 weeks postinjury (i.e., 4 weeks post-injection). In our study we used a less severe contusion injury but found a lower BMSC survival at time points that were close (acute injection, 28 days survival here vs. 35 days survival observed by Hofstetter et al. [2002]) or exactly matching (7-day delayed injection, 28 days survival here vs. 35 days survival observed by Hofstetter et al. [2002]), namely, 0.02 vs. 0.17 and 0 vs. 0.99 , respectively. A possible explanation for this discrepancy is that in Hofstetter et al. (2002) the BMSCs were injected $2 \mathrm{~mm}$ rostral and caudal as well as into the contusion lesion. It was not studied whether the surviving BMSCs were in fact those injected near rather than in the contusion, as has been described for a similar paradigm in a 7-day-old mouse spinal cord contusion model (Lee et al., 2003). Others have reported BMSC survival in spinal cord lesions but without quantification (Ankeny et al., 2004; Ohta et al., 2004; Zurita and Vaquero, 2004, 2006; de Haro et al., 2005; Cizkova et al., 2006).

Hofstetter et al. (2002) injected BMSCs into the contused spinal cord acutely or 1-week delayed and examined locomotor function of the hind limbs during the ensuing weeks. Both groups were not directly compared and tested for significance, but the data from this study indicated that improved BMSC survival was associated with improved locomotor function (Hofstetter et al., 2002). In general, this agrees with our data that improved survival of transplanted BMSCs elicits positive effects on spinal cord repair. Studies that investigate the correlation between BMSC survival and motor and sensory function are in progress.

Survival of grafted BMSCs during the first week post-injection was significantly lower when the cells were grafted 7 and 21 days post-injury compared to $15 \mathrm{~min}$ and 3 days postinjury. Normally, immune cells invade contused tissue rapidly to be followed by inflammatory cells including macrophages. The peak in macrophage presence is around 7 days post-injury, to recede thereafter (Blight, 1992; Popovich et al., 1997; Jones et al., 2005). We found that BMSCs survived best when injected immediately or 3 days after injury, which is when the number of inflammatory cells is still increasing in 

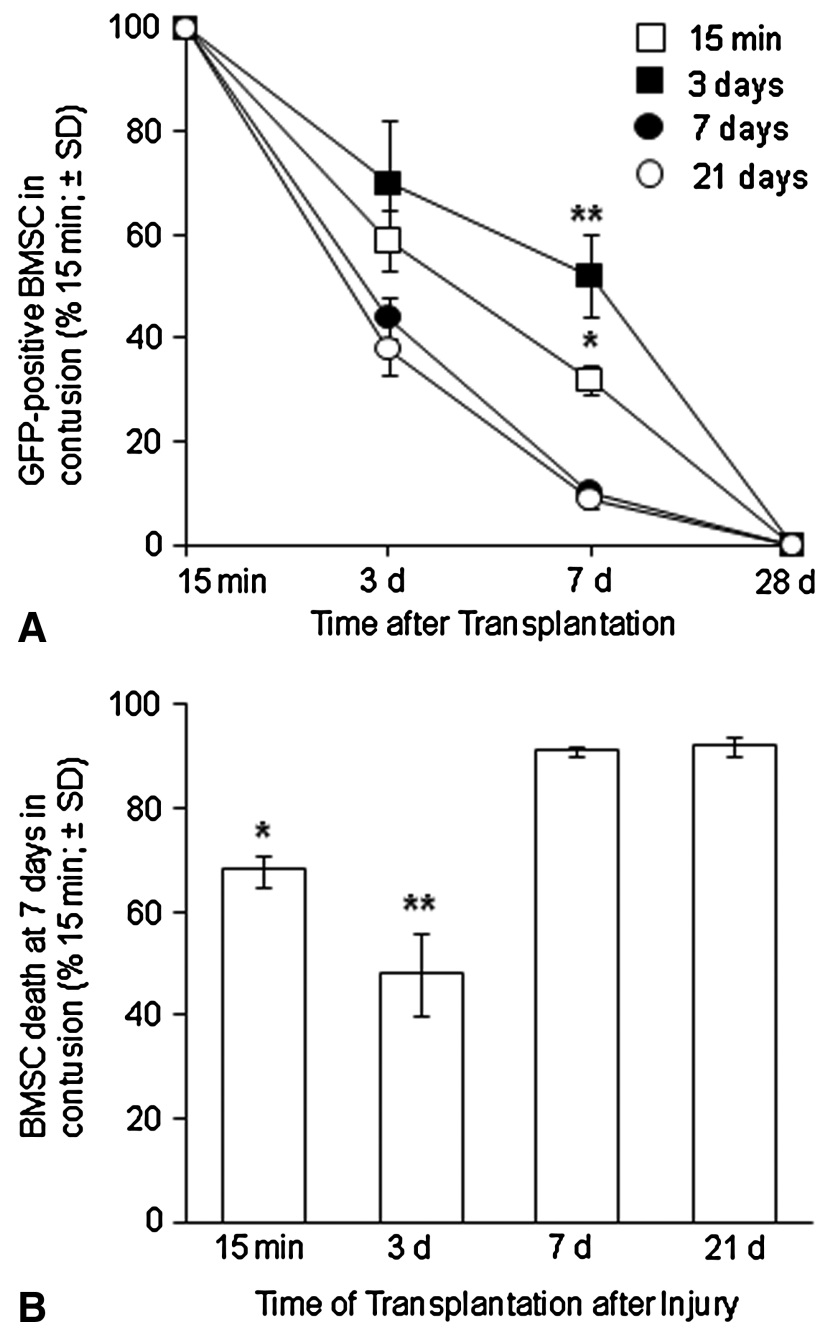

FIG. 4. BMSC survival in a moderate contusion in the adult rat thoracic spinal cord is low. (A) The number of BMSCs transplanted acutely ( $15 \mathrm{~min}$ post-injury) or delayed $(3,7$, and 21 days post-injury) into a moderate contusion decreases over 28 days post-injection. The numbers are expressed as a percentage of the numbers found at $15 \mathrm{~min}$ post-injection. (B) BMSC death within the moderate contusion at 7 days post-injection is significantly lower after acute and 3-day delayed injections than with 7- and 21-day delayed injections. Percentages are relative to the number at $15 \mathrm{~min}$ posttransplantation. Bars represent standard error of the mean. ${ }^{*} p<0.01 ;{ }^{* *} p<0.005$.

the contusion lesion. Possibly, macrophages are directly involved in transplanted BMSC loss, which would explain the greater loss at injection times when more macrophages can be found in the contusion. The relationship between macrophages and transplanted BMSCs within the injured spinal cord is still poorly understood.

We observed that some of the transplanted BMSCs migrated from the contusion into the rostral and caudal white matter. To our knowledge, this is the first evidence that BMSCs transplanted into a contusion site in the adult rat thoracic spinal cord migrate into the adjacent nervous tissue. Neuhuber and colleagues (2005) described that human BMSCs grafted in a hemisection in the adult rat cervical spinal
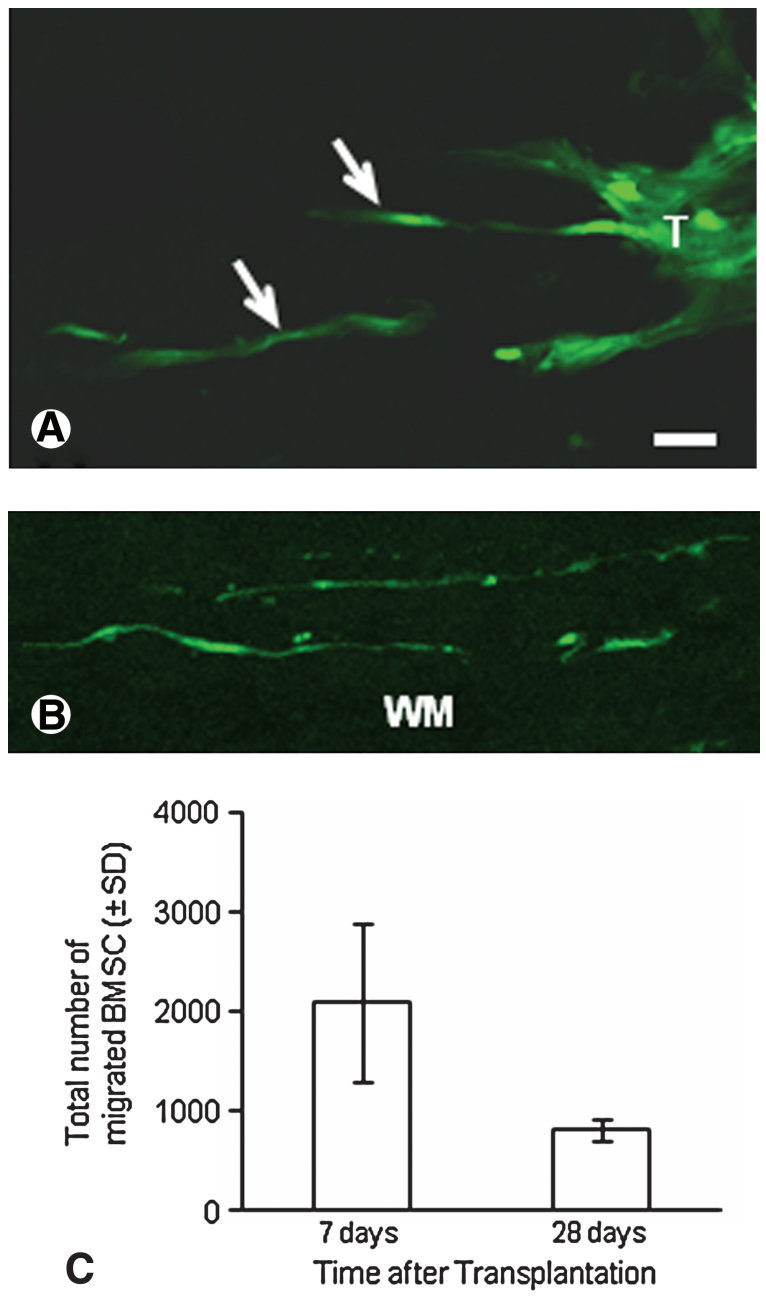

FIG. 5. BMSC transplanted into the moderately contused adult rat spinal cord contusion migrate into spinal cord white matter. (A) GFP-positive BMSC (arrow) "leaving" the transplant (T) at its rostral edge. (B) Several GFP-positive BMSC that have migrated approximately $5 \mathrm{~mm}$ into the rostral lateral white matter (WM). (C) Bar graph showing the number of BMSC that migrated out of a transplant at 7 and 28 days post-injection. BMSC were injected at 3 days postinjury. All microphotograph confocal images are from horizontal $20 \mu \mathrm{m}$ thick cryostat sections. (A) Scale bar, $15 \mu \mathrm{m}$ in A and $\mathrm{B}$.

cord migrated into the nearby spinal tissue. Our data suggested that the conditions at and nearby the 3-day-old spinal cord contusion permitted migration of the injected BMSCs. In the injured adult central nervous system, chemotactic factors and cytokines such as macrophage inflammatory protein- $1 \alpha$, monocyte chemoattractant protein- 1 , and interleukin- 8 have been implicated in BMSC migration (Wang et al., 2002).

In sum, we have gathered evidence that BMSCs transplanted immediately and 3 days after a contusion survive better within the lesion environment during the first week after injection compared to BMSC transplanted at 7 and 21 days post-injury. The improved survival is transient but the BMSC transplant elicited neuroprotective effects that resulted in improved tissue sparing up to 28 days after injection. 


\section{Acknowledgments}

We thank L. Riveron for cell culture; Y. Abajas, V. Rodriguez, B. Bliesner, and M. Velez for histology; T. Nandoe Tewarie, B. Frydel, and B. Shaw for image analysis. The Miami Project viral vector core provided the lentiviral vectors. The animal core facilities at the Miami Project and the International Center for Spinal Cord Injury injured and maintained the rats. This work was sponsored by grant 017.001.265 from the Netherlands Organization for Scientific Research, the Kennedy Krieger Institute, and the Department of Physical Medicine and Rehabilitation at the University of Pittsburgh.

\section{Author Disclosure Statement}

No conflicting financial interests exist.

\section{References}

Ankeny, D.P., McTigue, D.M., and Jakeman, L.B. (2004). Bone marrow transplants provide tissue protection and directional guidance for axons after contusive spinal cord injury in rats. Exp. Neurol. 190, 17-31.

Azizi, S.A., Stokes, D., Augelli, B.J., DiGirolamo, C., and Prockop, D.J. (1998). Engraftment and migration of human bone marrow stromal cells implanted in the brains of albino rats-similarities to astrocyte grafts. Proc. Natl. Acad. Sci. USA 95, 3908-3913.

Barnett, S.C., and Riddell, J.S. (2007). Olfactory ensheathing cell transplantation as a strategy for spinal cord repair: what can it achieve? Nat. Clin. Pract. Neurol. 3, 152-161.

Basso, D.M., Beattie, M.S., and Bresnahan, J.C. (1995). A sensitive and reliable locomotor rating scale for open field testing in rats. J. Neurotrauma 12(1), 1-21.

Blight, A.R. (1992). Macrophages and inflammatory damage in spinal cord injury. J. Neurotrauma 9, S83-91.

Blits, B., Kitay, B.M., Farahvar, A., Caperton, C.V., Dietrich, W.D., and Bunge, M.B. (2005). Lentiviral vector-mediated transduction of neural progenitor cells before implantation into injured spinal cord and brain to detect their migration, deliver neurotrophic factors and repair tissue. Restor. Neurol. Neurosci. 23, 313-324.

Boiret, N., Rapatel, C., Veyrat-Masson, R., Guillouard, L., Guérin, J.J., Pigeon, P., Descamps, S., Boisgard, S., and Berger, M.G. (2005). Characterization of nonexpanded mesenchymal progenitor cells from normal adult human bone marrow. Exp. Hematol. 33, 219-225.

Chen Q., Long, Y., Yuan, X., Zou, L., Sun, J., Chen, S., PerezPolo, J.R., Yang, K. (2005). Protective effects of bone marrow stromal cell transplantation in injured rodent brain: synthesis of neurotrophic factors. J. Neurosci. Res. 80, 611-619.

Cizkova, D., Rosocha, J., Vanicky, I., Jergova, S., and Cizek, M. (2006). Transplants of human mesenchymal stem cells improve functional recovery after spinal cord injury in the rat. Cell. Mol. Neurobiol. 26, 1165-1178.

de Haro, J., Zurita, M., Ayllón, L., and Vaquero, J. (2005). Detection of 111In-oxine-labeled bone marrow stromal cells after intravenous or intralesional administration in chronic paraplegic rats. Neurosci. Lett. 377, 7-11.

Delorme, B., and Charbord, P. (2007). Culture and characterization of human bone marrow mesenchymal stem cells. Methods Mol. Med. 140, 67-81.

Garcia, R., Aguiar, J., Alberti, E., de la Cuetara, K., and Pavon, N. (2004). Bone marrow stromal cells produce nerve growth factor and glial cell line-derived neurotrophic factors. Biochem. Biophys. Res. Comm. 316, 753-754.

Gruner, J.A. (1992). A monitored contusion model of spinal cord injury in the rat. J. Neurotrauma 9, 123-128.

Hagg, T., and Oudega, M. (2006). Degenerative and spontaneous regenerative processes after spinal cord injury. J. Neurotrauma 23, 264-280.

Hofstetter, C.P., Schwarz, E.J., Hess, D., Widenfalk, J., El Manira, A., Prockop, D.J., and Olson, L. (2002). Marrow stromal cells form guiding strands in the injured spinal cord and promote recovery. Proc. Natl. Acad. Sci. USA 99, 2199-2204.

Hurtado, A., Moon, L.D., Maquet, V., Blits, B., Jerome, R., and Oudega, M. (2006). Poly (D,L-lactic acid) macroporous guidance scaffolds seeded with Schwann cells genetically modified to secrete a bi-functional neurotrophin implanted in the completely transected adult rat thoracic spinal cord. Biomaterials $27,430-442$.

Jones, T.B., McDaniel, E.E., and Popovich, P.G. (2005). Inflammatory-mediated injury and repair in the traumatically injured spinal cord. Curr. Pharm. Des. 11, 1223-1236.

Lee, J., Kuroda, S., Shichinohe, H., Ikeda, J., Seki, T., Hida, K., Tada, M., Sawada, K., and Iwasaki, Y. (2003). Migration and differentiation of nuclear fluorescence-labeled bone marrow stromal cells after transplantation into cerebral infarct and spinal cord injury in mice. Neuropathology 23, 169-180.

Mahmood, A., Lu, D., and Chopp, M. (2004). Intravenous administration of marrow stromal cells (MSCs) increases the expression of growth factors in rat brain after traumatic brain injury. J. Neurotrauma 21, 33-39.

Naldini, L., Blomer, U., Gage, F.H., Trono, D., and Verma, I.M. (1996). Efficient transfer, integration, and sustained long-term expression of the transgene in adult rat brains injected with a lentiviral vector. Proc. Natl. Acad. Sci. USA 93, 11382-11388.

Nandoe Tewarie, R.D., Hurtado, A., Levi, A.D., Grotenhuis, A., and Oudega, M. (2006). Bone marrow stromal cells for repair of the spinal cord: towards clinical application. Cell Transplant 15, 563-577.

Neuhuber, B., Himes, B.T., Shumsky, J.S., Gallo, G., and Fischer, I. (2005). Axon growth and recovery of function supported by human bone marrow stromal cells in the injured spinal cord exhibit donor variations. Brain Res. 1035, 73-85.

Ohta, M., Suzuki, Y., Noda, T., Ejiri, Y., Dezawa, M., Kataoka, K., Chou, H., Ishikawa, N., Matsumoto, N., Iwashita, Y., Mizuta, E., Kuno, S., and Ide, C. (2004). Bone marrow stromal cells infused into the cerebrospinal fluid promote functional recovery of the injured rat spinal cord with reduced cavity formation. Exp. Neurol. 187, 266-278.

Oudega, M., and Xu, X.M. (2006). Schwann cell transplantation for repair of the adult spinal cord. J. Neurotrauma 23, 453-467. Patist, C.M., Mulder, M.B., Gautier, S.E., Maquet, V., Jérôme, R., and Oudega, M. (2004). Freeze-dried poly (D,L-lactic acid) macroporous guidance scaffolds impregnated with brainderived neurotrophic factor in the transected adult rat thoracic spinal cord. Biomaterials 25, 1569-1582.

Popovich, P.G., Wei, P., and Stokes, B.T. (1997). Cellular inflammatory response after spinal cord injury in SpragueDawley and Lewis rats. J. Comp. Neurol. 377, 443-464.

Rasmusson, I., Ringden, O., Sundberg, B., and Le Blanc, K. (2005). Mesenchymal stem cells inhibit lymphocyte proliferation by mitogens and alloantigens by different mechanisms. Exp. Cell Res. 305, 33-41.

Ruitenberg, M.J., Plant, G.W., Hamers, F.P., Wortel, J., Blits, B., Dijkhuizen, P.A., Gispen, W.H., Boer, G.J. and Verhaagen, J. (2003). Ex vivo adenoviral vector-mediated neurotrophin gene 
transfer to olfactory ensheathing glia: effects on rubrospinal tract regeneration, lesion size, and functional recovery after implantation in the injured rat spinal cord. J. Neurosci. 23, 7045-7058.

Song, S., Kamath, S., Mosquera, D., Zigova, T., Sanberg, P., Vesely, D.L., Sanchez-Ramos, J. (2004). Expression of brain natriuretic peptide by human bone marrow stromal cells. Exp. Neurol. 185, 191-197.

Takami, T., Oudega, M., Bates, M.L., Wood, P.M., Kleitman, N., and Bunge, M.B. (2002). Schwann cell but not olfactory ensheathing glia transplants improve hindlimb locomotor performance in the moderately contused adult rat thoracic spinal cord. J. Neurosci. 22, 6670-6681.

Tse, W.T., Pendleton, J.D., Beyer, W.M., Egalka, M.C., and Guinan, E.C. (2003). Suppression of allogeneic T-cell proliferation by human marrow stromal cells: implications in transplantation. Transplantation 75, 389-397.

Wang, L., Li, Y., Chen, X., Chen, J., Gautam, S.C., Xu, Y., and Chopp, M. (2002). MCP-1, MIP-1, IL-8 and ischemic cerebral tissue enhance human bone marrow stromal cell migration in interface culture. Hematology 7, 113-117.

Wu, S., Suzuki, Y., Ejiri, Y., Noda, T., Bai, H., Kitada, M., Kataoka, K., Ohta, M., Chou, H., and Ide, C. (2003). Bone marrow stromal cells enhance differentiation of cocultured neuro- sphere cells and promote regeneration of injured spinal cord. J. Neurosci. Res. 72, 343-351.

Yoshihara, H., Shumsky, J.S., Neuhuber, B., Otsuka, T., Fischer, I., and Murray, M. (2006). Combining motor training with transplantation of rat bone marrow stromal cells does not improve repair or recovery in rats with thoracic contusion injuries. Brain Res. 1119, 65-75.

Zurita, M., and Vaquero, J. (2004). Functional recovery in chronic paraplegia after bone marrow stromal cells transplantation. Neuroreport 15, 1105-1108.

Zurita, M., and Vaquero, J. (2006). Bone marrow stromal cells can achieve cure of chronic paraplegic rats: functional and morphological outcome one year after transplantation. Neurosci. Lett. 402, 51-56.

Address correspondence to: Martin Oudega, Ph.D.

University of Pittsburgh School of Medicine W1452 Thomas E. Starzl Biomedical Science Tower 200 Lothrop Street Pittsburgh, PA 15213

E-mail: moudega@pitt.edu 